\title{
ОСОБЕННОСТИ ВЗАИМОДЕЙСТВИЯ ЗАКОНОДАТЕЛЬНОЙ И ИСПОЛНИТЕЛЬНОЙ ВЛАСТИ В ПАРЛАМЕНТСКОЙ МОНАРХИИ: ОПЫТ СОВРЕМЕННОЙ ЯПОНИИ
}

\author{
(c) 2021 Попова О.С. \\ доцент кафедры менеджмента, кандидат экономических наук \\ Государственный институт экономики финансов права и технологий, Россия, Гатчина \\ Popova.olse@gmail.com \\ () 2021 Иванов М.Д. \\ Государственный институт экономики финансов права и технологий, Россия, Гатчина \\ Maxkeeper13@inbox.ru \\ (c) 2021 Якимчук Н.H. \\ доцент кафедры менеджмента, кандидат политических наук \\ Государственный институт экономики, финансов, права и технологий, Россия, Гатчина \\ yakimchuk777@bk.ru \\ (c) 2021 Иванова М.В. \\ доцент высшей школы административного управления, кандидат экономических наук \\ Санкт-Петербургский политехнический университет Петра Великого, Россия, Санкт-Петербург \\ ivanova.mv@spbstu.ru
}

Парламентские монархии разительно отличаются от республик структурой власти. Современные парламентские монархии различны даже между собой, что делает их изучение особенно сложным, и требует глубокого анализа каждого такого государства. Современное государственное устройство Японии характеризуется аутентичностью политических традиций, совместно с современными реформами, пришедшими от США в послевоенное время. Расстановка политических сил в Японии, которая на первый взгляд представляется несложной, на самом же деле имеет огромное количество нюансов и спорных решений.

Ключевые слова: Япония; парламент; взаимодействие властей; Император; Правительство; система сдержек и противовесов.

В современном мире монархия, как элемент формы государства, сохраняется либо в ортодоксальных странах (Бруней, ОАЭ), либо в развитых, которые сохраняют монархию по причине исторических и политических традиций (Великобритания, Испания, Монако). Особенности формы правления парламентских монархий представляют большой интерес, так как сочетают феодальные способы передачи власти главы государства и демократические способы формирования государственных органов.

Современная Япония является самым ярким примером азиатской парламентской монархии. Несмотря на то, что в создании Конституции, а значит основ политического и социального строя Японии, участвовали страны победительницы Второй Мировой Войны, в том числе и США, государство сумело сохранить свои государственные и национальные традиции и осо- бенности. Примечательно, что американские эксперты изначально хотели сделать парламент Японии однопалатным - Япония не многонациональное государство, принцип федерализма не приживался. Однако японская сторона резко отвергла такую концепцию - японцы считали, что верхняя палата будет «институтом здравого смысла». В итоге была принята концепция парламента, которая действует до сих пор: нижняя палата - это поле партийной политики, тогда как верхняя палата призвана наблюдать за соблюдением интересов в политической игре [3, с. 84].

Парламент Японии состоит из двух палат: Палата Представителей (нижняя палата) и Палата Советников (верхняя палата) [3, с. 84]. Способы формирования палат - процесс сложный и неординарный. Палата Представителей формируется по смешанной системе выборов (часть 
парламентариев избирается по одномандатным округам, а часть по партийным спискам). В случае с партийными выборами Япония делится на 11 округов пропорционального представительства, представляющих собой блоки из нескольких префектур [3, с. 156]. Интересно, что при каждом новом созыве нижней палаты, число парламентариев меняется. Связанно это с тем, что количество представителей прямо пропорционально населению государства, которое последние пять лет стабильно идет на убыль. Так, количество парламентариев уменьшилось на сегодняшний день до 465. Более того, жесткой регламентации процента «одномандатников» и партийных представителей нет. Однако, примерно 60-65\% отдается депутатам, которые избираются по мажоритарной системе. В 2019 году «одномандатников» было 289, когда как партийных представителей 176 [5]. Выборы в нижнюю палату парламента проводятся раз в 4 года [3, с.156]. Для того, чтобы выставить свою кандидатуру на парламентские выборы, необходимо минимум за 4 дня до выборов уведомить соответствующее подразделение органа МСУ о желании участвовать, и приложить к письму государственную облигацию. В одномандатном округе действует система относительного большинства голосов. В пропорциональной части выборов партии предоставляют избирательной комиссии списки своих членов, которые могут пройти в парламент [3, с. 156], при подсчете голосов используют метод бельгийского математика Д’Ондта. Похожая система выборов практикуется и в верхней палате парламента Японии. В Палате Советников 245 мест, из которых 147 избираются по префектуриальным избирательным округам (одномандатники), а 98 по ОПП (округи пропорционального представительства) [3, с. 159]. Половина Палаты Советников обновляется каждые три года. Так, в 2019 году японцы избирали 124 депутата. Данная процедура могла бы обеспечить хорошую сменяемость власти, однако количество сроков в парламенте не ограничивается и, большинство членов Палаты Советников занимают свою должность второе десятилетие [4].

Главная функция парламента Японии - законотворчество. В Японии, законодательной инициативой обладает парламент и Кабинет, однако сам процесс законотворчества и принятие акта принадлежит именно парламенту. Принятие бюджета страны принадлежит высшему за- конодательному органу. Парламент так же принимает поправки в конституцию, но при этом, их утверждение зависит от голосования граждан на референдуме. Подписание и ратификация международных нормативно-правовых актов, назначение премьер-министра Японии, высказывание вотума доверия правительству, назначение или решение о назначении высших должностных лиц государства, образование из членов обеих палат суда, для рассмотрения дел по импичменту, введение в стране или в районах стихийных бедствий чрезвычайного положения, одобрение использования военных сил для самообороны тоже входит в компетенцию парламента. Парламент выступает «трибуной» для обсуждения важнейших общегосударственных вопросов [3, с. 83-84]. Обе палаты сами выбирают своих спикеров, должностных лиц, сами определяют продолжительность сессии, ее расписание, т.е. палаты парламента сами определяют свой внутренний распорядок [3, с. 85]. Соответственно, Палата Представителей и Палата Советников независимы и равны. Однако де-факто у Палаты Представителей полномочий немного больше. Например, именно из числа Палаты Представителей избирается премьер-министр и часть Кабинета, только Палата Представителей может объявить вотум недоверия Правительству, то есть, по большому счету, именно Палата Представителей контролирует деятельность Кабинета [3, с. 85-86]. Однако неправильно будет недооценивать Палату Советников, ведь для принятия поправок необходимо квалифицированное большинство парламента, а не только нижней палаты. Также, несмотря на формирование исполнительной власти Палатой Представителей, Правительство несет ответственность перед всем парламентом. Палата Советников, в отличие от нижней палаты парламента, не может быть распущена - ее деятельность, в соответствии с Конституцией будет приостановлена, однако премьер-министр может созвать верхнюю палату, ведь в соответствии с 54 статьей Конституции Японии, новые парламентские выборы должны начаться в течение сорока дней, а парламент созывается на тридцатый день после выборов. Получается, что в течение семидесяти дней парламент не функционирует. Премьер-министр может созвать экстренное заседании верхней палаты, именно для того случая, если в эти 70 дней произойдет какая-либо чрезвычайная ситуация, и чтобы управление 
государством могло осуществляться хотя бы одной палатой [3, с. 86-87]. Вопрос о реальном положении палат иллюстрирует следующий факт - после принятия закона большинством членов Палаты Представителей, закон уходит на согласование в Палату Советников. Однако в случае отклонения закона верхней палатой, закон возвращается обратно на пересмотр в Палату Представителей, которой достаточно двух третьих голосов для одобрения закона (при кворуме в одну треть) [1].

Император - символ государства и единства народа (Глава 1, статья 1) [1]. Императорский титул передается по наследству. Передача престола происходит по салической системе: наследником может быть только лицо мужского пола, предпочтение отдаётся старшему сыну. Однако история Японии знает 8 женщин-императриц. Связанно это с тем, что законный наследник, старший сын, на момент передачи престола был младенцем [2, с. 81]. У Императора есть 3 символа его власти: зеркало, яшмовые подвески и меч [2, c. 80-81]. Несмотря на то, что с 1946 года Император не является «потомком бога», а является обычным смертным, его статус высшего жреца Синто (национальная религия Японии) остается [2, с. 81]. Некоторые традиционные полномочия монарха у японского Императора отсутствуют, например, право отлагательного вето. В соответствии с Конституцией Японии (статья 7), Император по совету и одобрению Кабинета может назначать и отстранять государственных министров, то есть формировать Кабинет. Но по факту, он почти в этом не участвует. На практике это происходит так. Премьер-министр навещает Императора и сообщает ему «Я избран премьером и приступаю к формированию правительства». Император отвечает: «Желаю успехов». Таким образом, Император не может оказывать существенного влияния на формирование и деятельность исполнительной власти [2, с. 82]. Вся политическая деятельность Императора характеризуется 3 статьей Конституции: «Все действия Императора, относящиеся к делам государства, могут быть предприняты не иначе как с совета и одобрения Кабинета, и Кабинет несет за них ответственность» [1]. На Императоре лежит обязанность по ратификации международных договоров, но делать он это может только по одобрению Кабинета. По Конституции, внешнеполитическую деятельность осуществляет Кабинет, однако Император Японии необходим во внешнеполитической деятельности как ди- пломатическая фигура, ведь визит Императора в другие страны приносит большой вклад в процесс переговоров. [2, с. 83]. Т. е. Император почти никак не влияет на политическую сферу, однако он выполняет более важную функцию - он сохраняет единство нации, ее целостность.

Кабинет Японии - высший орган исполнительной власти. В соответствии с Конституцией Японии, Кабинет формируется следующим образом: на совместном заседании обеих палат парламента принимается резолюция выдвижения кандидата на пост Премьер-Министра - главы Кабинета, и, соответственно, главы исполнительной власти. Как правило, Премьерминистром является глава партии большинства в Парламенте [1]. Однако в случае, если палаты выдвинули разных кандидатов, или Палата Coветников не представила кандидатуру, то решение Палаты Представителей становится окончательным 3, с. 112]. После, Премьер-министр назначает министров, при этом, в 68 статье Конституции регламентировано, что «большинство министров должно быть избрано из числа членов Парламента» [1]. Однако на данный момент, все министры Кабинета являются парламентариями [6]. Нет ограничения по палатам или партиям, министром может быть, как член нижней, так и член верхней палаты парламента. Министры совмещают парламентскую и правительственную деятельность, именно поэтому, в Кабинете Японии происходят частые ротации. Характерной чертой главного исполнительного органа Японии является отсутствие «министров без портфеля», причем раньше они были, однако для снижения уровня бюрократии, общее число министров было сокращено с 22 до 14 [3, с. 185]. В 2001 году Кабинет Японии перешел на новую структуру органа: 1 канцелярия, 1 комиссия, 10 министерств и 1 управление (с 2007 года управление было упразднено в пользу еще одного министерства) [3, с. 185]. На данный момент, в Кабинет Японии, кроме Премьера, еще 20 министров, 11 из которых в соответствии традиционными министерствами, определенными в 2001 году, и еще 9 министров, закрепленными как «Министр по вопросам...» или «Министр по делам...». Также, у Министра есть по 2 заместителя - парламентский (который приходит и уходит вместе с министром), и административный, который остается на своем посту, несмотря на смену министра. Причем некоторые министры имеют по 2 заместителя административных и парламентских, например - Министр экономики [6]. 
Структура Кабинета Японии достаточно сложная, и связанно это с тем, что Кабинет определяет главные направления политики страны. Среди различных органов Кабинета, которые курируют какую-то отдельную сферу, необходимо выделить Секретариат Кабинета министров (Найкакукомбо). Это технический орган Правительства Японии, который занимается исключительно административной деятельностью: обеспечение регулярных заседаний кабинета, подготовка необходимой информации, протоколирование заседаний и прочее [3, с. 176, 183]. Помимо Секретариата, важную роль играет Законодательное Бюро Кабинета министров (НайкакуХосэйкёку). Цель этого бюро состоит в том, что они проверяют вносимые различными ведомствами законопроекты, на предмет соответствия действующему законодательству [3, с. 183]. Примечательно, что по данным официального сайта Кабинета Министров Японии, в состав Законодательного Бюро входят: 1 член Палаты Представителей, 1 член Палаты Советников, и 2 внепарламентских министра [6].

К полномочиям Кабинета Японии относятся: проводить в жизнь законы, управлять государственной политикой (как внутренней, так и внешней), заключать международные договоры (при одобрении парламента), управлять государственной службой, разрабатывать и осуществлять государственный бюджет, издавать правительственные указы в целях исполнения конституции, принимать решения об общей или частной амнистии и прочее [1]. Закон о структуре государственного управления регламентирует функции членов Кабинета - министров. В соответствии с этим законом, министры и руководители ведомств: решают дела внутри своего ведомства, вносят на имя Премьер-министра утверждения проекта решений (в соответствии с профильной деятельностью), издают распоряжения в соответствии со своей компетенцией, выступают с публичным заявлением или изданием приказа в отношении вопроса, входящего в их компетенцию, осуществляют руководство и контроль в отношении глав местных органов власти [1, с. 178].

При такой организации взаимодействия законодательной и исполнительной власти можно вести речь о «кабинетно-парламентской монархии» [1, с. 371]. Кабинет министров подотчетен Парламенту [1, с. 60]. На практике так и происходит - Премьер докладывает парламенту о состоянии государственных дел [1, с. 60,61]. При этом Премьер-министр является фактическим главой государства. Отличным примером взаимодействия парламента и Кабинета, будет законодательная деятельность. Дело в том, что законодательную инициативу имеет и Кабинет, и парламент, причем в равной степени [1]. Необходимо отметить, что Япония, в начале своей послевоенной истории, шла по пути США в распределении законотворческих полномочий (все законопроекты с самого начала разрабатываются и принимаются парламентом). Японцы первоначально делали так же, отдав пальму законодательного первенства парламенту. Однако уже к 1950-м годам, правительственные законопроекты стали вытеснять парламентские. Обуславливается это тем, что у Кабинета более развитая и богатая разноплановыми специалистами кадровая структура [3, с. 115]. На данный момент, более 70\% законопроектов, рассматриваемых в парламенте, являются правительственными. Кабинет подготавливает законы намного быстрее и качественнее, с юридической точки зрения, не зря же в состав Кабинета входит Законодательное Бюро. «Правительственные законопроекты представляют собой тщательно подготовленные юридические документы, в подавляющем большинстве не требующие поправок и исправлений в ходе парламентских слушаний. Этому способствует многоэтапный процесс подготовки и согласования законопроектов в структурах исполнительной власти на предпарламентской стадии» [3, с. 119].

Стоит отдельно рассмотреть взаимодействие властей в сфере сдержек и противовесов. Палата Представителей Японии может вынести вотум недоверия правительству. Это влечет за собой либо отставку Кабинета, либо роспуск Палаты Представителей и досрочные парламентские выборы [1]. Более того, Премьер-министр может распустить Палату Представителей по своему желанию. В последние годы это встречалось часто, например, роспуски в 2014 и 2017 годах Премьером Абэ. Делал он это для проведение экономическом политики, которую в народе называли «абэкономика». В тех ситуациях он был не уверен в поддержке парламентом его идей, поэтому распускал Палату Представителей. В этом случае, граждане Японии, на досрочных выборах могут сами повлиять на потенциальные реформы. Таким образом, Абэ распускал нижнюю палату парламента, чтобы заручиться поддержкой избирателей и своей партии. По итогу каждые досрочные парламентские выборы в Парламент 
в 2014 и 2017 годах показывали готовность граждан к экономическим реформам, ведь в обоих случаях ЛДП (Либерально-Демократическая Партия), лидером которой был Абэ, получало парламентское большинство [9]. Решение о досрочном роспуске нижней палаты, по большому счету, является политической традицией. За последние 10 лет Палата Представителей была распущена 3 раза - 2012, 2014 и 2017. Стоит отметить, что крайний созыв 2017 года досидел не до конца срока, а до этого года, Палата Представителей досиживала лишь созыв 2005-2009 годах $[7,8,9]$. Официальное объявление о роспуске нижней палаты делает Император. На совместном созыве обеих палат, Председатель Палаты Представителей зачитывает императорский указ о роспуске парламента. В 2017 году он звучал так «На основании седьмой статьи Конституции - нижняя палата распущена» [9]. При роспуске Палаты Представителей, Палата Советников приостанавливает свою деятельность, и возобновляет лишь по указу Премьера (в экстренных случаях), либо после формирования новой Палата Представителей.

У Палаты Советников есть право на вотум недоверия к конкретному должностному лицу Кабинета, например, в 2010-2012 годах, была ситуация, которую назвали «перекрученным парламентом». Палата Советников, в этот период 6 раз высказывала вотум недоверия членам Кабинета от Демократической Партии. Однако, данное право верхней палаты не обязывает
Премьера отстранять от должности министра с вотумом недоверия, но это отличный способ давления на Кабинет со стороны оппозиции Парламента [26, с. 147].

Еще один важным инструментом системы сдержек и противовесов политической игры Японии, можно считать запросы Правительству. Как правило, этот процесс происходит сразу после речи Премьер-министра на заседании Парламента, например, на первом созыве. Парламент задает интересующие его вопросы сначала Премьеру, а после, остальным должностным лицам Кабинета, в соответствии с их компетенцией. Обычно вопросы задаются в устной форме, и проговаривается сразу блок вопросов. У министра есть право на семидневный срок на подготовку письменного ответа, однако, если министр достаточно компетентен, то он имеет право дать ответ сразу после вопроса [3, с. 139].

Таким образом, Кабинет Японии - самый влиятельный орган политического устройства Японии. При этом для современного демократического государства важно, что члены Кабинета являются избранниками народа. Характерно, что, проводя реформы в различных областях, Премьер часто распускает Палату Представителей, для получения поддержки от народа.

Япония - государство, где политические традиции и механизмы взаимодействие законодательной и исполнительной власти, уникальны, а исторические устои отражены в системе органов государственного управления.

\section{Библиографический список}

1. Конституция Японии 1947 г. [Текст] // Конституции зарубежных государств / Сост. В. В. Маклаков. - 2-е изд. исправл. И доп. - М.: БЕК, 1999.

2. Головко, К.Э.Конституционно - правовой статус императора Японии.// Электронная библиотека БГУ. Сборник работ 64-й научной конфренции студентов и аспирантов Белгосуниверситета, 15-18 мая 2007 г., г. Минск: в 3 ч. / [редкол.: А. Г. Захаров (ответственный редактор) и др.]. - Минск, 2007. - Ч. 2. - С. 80-83

3. Политическая система современной Японии: Учеб. пособие для студентов вузов / Под ред. Д. В. Стрельцова. - М.: Аспект Пресс, 2013. - 384 с.

4. House of Councillors The National Diet of Japan // Members. [Электронный pecypc] URL: https://www.sangiin. go.jp/eng/member/officers/index.htm. (дата обращения 11.04.2021)

5. House of Representatives, Japan // Composition of the House. [Электронный pecypc] URL: https://www.shugiin. go.jp/internet/itdb_english.nsf/html/statics/member/mem_a.htm(дата обращения 11.04.2021)

6. Prime Minister of Japan and His Cabinet // List of Ministers (The Cabinet). [Электронный pecypc]. URL: https://japan.kantei.go.jp/99_suga/meibo/daijin/index_e.html(дата обращения 11.04.2021)

7. В Японии официально объявили о роспуске нижней палаты парламента.// РИА Новости. - 21.11.2014 [Новостной электронный ресурс] URL: https://ria.ru/20141121/1034402819.html(дата обращения: 11.04.2021)

8. В Японии распущен парламент.// Lenta.ru - 16.11.2012 [Новостной электронный ресурc] URL: https://lenta. ru/news/2012/11/16/dissolve/(дата обращения: 11.04.2021)

9. Император Японии объявил о роспуске нижней палаты парламента./ РИА Новости. - 28.09.2017 [Новостной электронный ресурс] URL: https://ria.ru/20170928/1505724148.html (дата обращения: 11.04.2021) 